\title{
CONHECIMENTO BOTÂNICO LOCAL EM UMA ÁREA DE ASSENTAMENTO rural no Piauí, nordeste do Brasil
}

\author{
Ethyênne Moraes Bastos ${ }^{*}$, Mauricio Eduardo Chaves e Silva ${ }^{2}$, Fábio José Vieira ${ }^{3}$, Roseli Farias \\ Melo de Barros ${ }^{4}$
}

\begin{abstract}
1,2Programa de Pós Graduação em Desenvolvimento e Meio Ambiente da Universidade Federal do Piauí - UFPI, Av. Universitária, 1310, 64049-550 Ininga, Teresina, PI, Brasil.

${ }^{3}$ Professor da Universidade Estadual do Piaui - UESPI, Campus Professor Barros Araújo, Av. Senador Helvidio Nunes, S/N, Junco, Picos, PI, Brasil.

${ }^{4}$ Professora da Universidade Federal do Piauí, Campus Universitário Ministro Petrônio Portella - Bairro Ininga, Departamento de Biologia. Teresina, PI, Brasil.
\end{abstract}

*Autor para correspondência: ethy_enne@hotmail.com

Recebido em 21 de junho de 2017. Aceito em 26 de março de 2018. Publicado em 20 de junho de 2018.

Resumo - O conhecimento sobre o uso dos recursos vegetais está densamente presente na cultura popular sendo transmitido pela oralidade ao longo das gerações. Deste modo, objetivou-se investigar o conhecimento botânico inserido na população de um assentamento rural no Piauí, tendo em vista a importância de se conhecer os usos e potencialidades dos recursos vegetais da localidade como fonte de transmissão dos saberes locais. Foram realizadas 57 entrevistas semiestruturadas, com residentes maiores de 18 anos. Ao total foram citadas 120 plantas como úteis, a maioria dessas plantas em apenas uma categoria de uso. Medicinal e alimentícia foram às categorias de maior representatividade com 24 e 17 espécies, respectivamente. A família botânica que se destacou em número de espécies foi a Fabaceae, com 18 espécies. Predominaram espécies nativas, encontradas especialmente na mata. A babosa (Aloe vera L) apresentou maior valor de uso entre as espécies. Constatou que a utilização das plantas varia conforme a categoria de uso em que os recursos vegetais foram alocados e mostrou, de modo geral, heterogêneo em relação à idade e ao gênero dos informantes. A oralidade é a forma de transmissão dos recursos conhecidos e utilizados pelos investigados, repassados entre as gerações.

Palavras-chave: Etnobotânica; Semiárido; Populações Rurais.

\section{Conocimiento botánico local en una zona rural en el Estado de Piauí, noreste de Brasil}

REsumen - El conocimiento del uso de los recursos vegetales está ampliamente presente en la cultura popular, y es transmitido de forma oral a lo largo de las generaciones. De este modo, el objetivo de este estudio fue investigar el conocimiento botánico en la población de un asentamiento rural en el Estado de Piauí, Brasil, considerando la importancia del conocimiento de los usos y de las potencialidades de los recursos vegetales de la región como fuente de transmisión de los saberes locales. Se realizaron 57 entrevistas semiestructuradas a los residentes mayores de 18 años. En total, se citaron 120 plantas como útiles; la mayoría de ellas se clasificaron en una sola categoría de uso. Las categorías medicinal y alimenticia fueron las de mayor representatividad, con 24 y 17 especies, respectivamente. La familia botánica Fabaceae se destacó en cuanto al número de especies (18). Hubo una predominancia de especies nativas, encontradas especialmente en el bosque. La babosa (Aloe vera L) presentó el mayor valor de uso entre las especies. Se constató que el uso de las plantas varía según la categoría de uso asignada a los recursos vegetales y que, en general, hay una heterogeneidad en relación a la edad y al género de los informantes. La oralidad es la forma de transmisión del conocimiento de los recursos conocidos y utilizados por los investigados, traspasado entre las generaciones. 
Palabras clave: Etnobotánica; Semlárido; Poblaciones Rurales.

\title{
Local botanical knowledge in rural settlement in Piauí, Northeast Brazil
}

\begin{abstract}
AвSTRACT - The knowledge on use of vegetal resources has been orally transmitted from one generation to another and is densely present in popular culture. Thus, the objective of this study was to investigate the botanical knowledge inserted in the population of a rural settlement in Piauí, considering the importance of knowing the uses and potential of the local vegetal resources as a source of transmission of the local knowledge. 57 semi-structured interviews were conducted with residents older than 18 years. A total of 120 plants were cited as useful, most of these plants in only one category of use. The most representative categories, respectively, were medicinal and alimentary, with 24 and 17 species. The botanical family that stood out in the number of species was the Fabaceae with 18 species. Native species, found especially in the forest, predominated. Among all the species, the babosa (Aloe vera $\mathrm{L}$ ) has shown the highest value of use. It was found that the use of the plants varies according to the category of use in which the plant resources were allocated. In general, it is heterogeneous in relation to the informants' age and gender. The interviewees' knowledge on known and used resources is transferred orally from one generation to another.
\end{abstract}

Keywords: EthNobotany; SeMlarid; Rural Populations.

\section{INTRODUÇÃO}

As populações locais, em geral, possuem uma proximidade e apresentam elevado conhecimento do ambiente a sua volta. Isto ocorre, dentre outros motivos, pela necessidade de explorar os recursos que serão utilizados para as mais variadas finalidades (Amorozo, 2002). Para a autora, as comunidades rurais, em geral, possuem conhecimento de uso geral dos recursos vegetais, especialmente sobre plantas medicinais e estas informações são trocadas entre os indivíduos num processo dinâmico de aquisição e perda. No entanto, à medida que a relação com a terra se transforma pela modernização do campo e o contato com a sociedade nacional se intensifica, seja pelos meios de comunicação ou por agentes sociais, a rede de transmissão do conhecimento sobre plantas pode sofrer alterações.

O uso dos recursos vegetais está presente na cultura popular que é transmitida oralmente ao longo das gerações. Diegues (2002) afirma que este conhecimento é encontrado junto a populações tradicionais e/ou contemporâneas, e pelo que se tem observado tende à redução ou mesmo ao desaparecimento quando sofre a ação inexorável da modernidade. Begossi (2001) cita ainda, a falta de interesse dos jovens em continuar com os trabalhos realizados pela comunidade, principalmente pela falta de incentivo de políticas públicas.

A Etnobotânica pode servir como auxílio na identificação de práticas adequadas ao manejo da vegetação. Além do mais, a valorização e a vivência das sociedades humanas locais podem embasar estudos sobre o uso adequado da biodiversidade, incentivando, não apenas o levantamento das espécies, como contribuindo para sua conservação (Fonseca-Kruel e Peixoto, 2004). A partir do saber etnobotânico de uma população local, agregamse fontes de informações que são base de estudos descritivos dessas populações, que utilizam as plantas na medicina popular, na alimentação, manufatura, construção, rituais, entre outros.

Diversos fatores influenciam a ampliação, a prática, a perpetuação ou a perda do conhecimento local e o uso dos recursos vegetais por grupos humanos. Características demográficas, culturais e econômicas como idade, gênero, escolaridade, atividade econômica desenvolvida, entre outras, são apontadas por pesquisadores como possíveis geradores de diferenciação intracultural do conhecimento local, assim como o uso dos recursos 
vegetais (Nesheim et al. 2006; Gavin e Anderson 2007; Reyes-Gracia et al. 2007; Voeks 2007, Camou-Guerrero et al. 2008).

Em geral, no Brasil, assentamentos rurais são formados por agricultores de diversas origens, e também são locais onde a agricultura é parcialmente voltada para a subsistência. No entanto, existem poucos estudos etnobotânicos, principalmente no Nordeste brasileiro.

Deste modo, objetivou-se investigar o conhecimento botânico local inserido na população do Assentamento Saco do Juazeiro, analisando as categorias de uso registradas, o valor de uso das espécies e a distribuição do saber local entre gênero e faixa etária, tendo em vista a importância de se conhecer os usos e potencialidades dos recursos vegetais da região como fonte de transmissão dos saberes local.

\section{MATERIAL E MÉtodos}

\section{Área de Estudo}

O município de São Miguel do Tapuio está localizado na mesorregião Centro-Norte Piauiense e dista cerca de $227 \mathrm{~km}$ de Teresina, com área de $5.206 \mathrm{~km}^{2}$. Os núcleos urbanos Juazeiro e Umburana situam-se no Projeto de Assentamento (PA) Saco do Juazeiro a $40 \mathrm{~km}$ da sede do município (Figura 1).

Figura 1- Mapa de localização da área de estudo

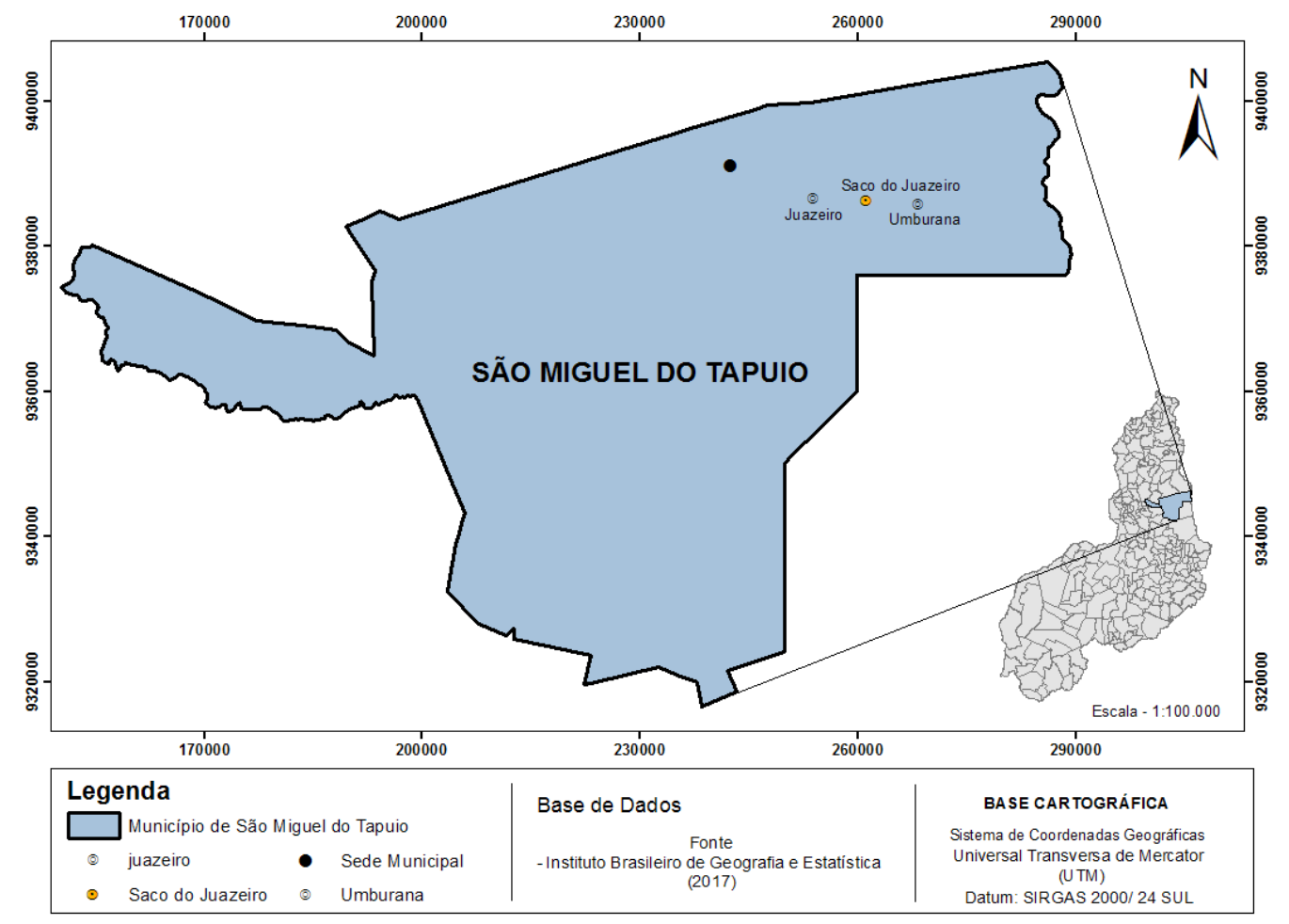

Fonte: Elaborado por Veloso, 2017.

O acesso é feito por uma estrada, que corta toda a área do PA e faz ligação ao município de Novo Oriente no Ceará. Prevalece como vegetação a caatinga arbustiva, com elementos de cerrado e mata semidecídua (Coimbra et al., 2008). 
Os núcleos estudados se caracterizam por possuírem escola municipal, posto de saúde, comércios, cemitério, poço tubular (coletivo) e telefone público, além das moradias serem constituídas por fossa séptica, cobertura de taipa e telha, piso revestido por cerâmica, cimento e chão batido, dispondo de energia elétrica e agua encanada. Os moradores encontram-se organizados e representados por Associação de Moradores, com desígnio amparar a população sobre os benefícios, ocorrências e realizações das atividades socioeconômicas.

De um modo geral, os habitantes dos núcleos estudados se caracterizam essencialmente rurais, com economia tipicamente familiar, sendo o feijão (Phaseolus vulgaris L.) o principal produto. Desenvolvem seu sistema de produção, combinando o plantio de culturas como milho (Zea mays L.), feijão (Phaseolus vulgaris L.) e melancia (Citrullus vulgaris Schrad) com criação de animais: galinha (Gallus domesticus), porcos (Sus domesticus) e gado (Bos taurus).

\section{Coleta e Análise de Dados}

A pesquisa foi conduzida em duas fases distintas, realizadas entre julho de 2010 a julho de 2011. Na primeira, realizaram-se visitas de reconhecimento da área e da população, para conhecimento histórico-cultural dos núcleos urbanos e identificação dos informantes. A mesma procedeu-se por meio de conversas informais e do acesso ao cadastro das unidades familiares dos núcleos pesquisados. Esse cadastro foi realizado pelos agentes comunitários de saúde presente em cada núcleo estudado. Com base nessas informações, contabilizaram-se 269 indivíduos, distribuídos em 74 unidades familiares. Dessa forma, utilizaram-se alguns critérios conforme Amorozo (1996), sendo selecionado um número máximo de três pessoas por família, efetivos residentes nos núcleos e maiores de 18 anos. Assim, o universo amostral compôs-se de 57 sujeitos, sendo 31 mulheres e 26 homens com idade variando entre 19 a 86 anos.

$\mathrm{Na}$ segunda, objetivou-se trabalhar diretamente com os informantes selecionados, utilizando-se entrevistas semiestruturadas (Bernard, 1988) usando formulários padronizados que abrangiam dados relativos aos aspectos socioeconômicos, culturais e etnobotânicos, para obtenção das plantas utilizadas pelos moradores como também acerca da transmissão oral do conhecimento.

Em relação à pesquisa das práticas culturais e dos aspectos socioeconômicos ocorreu por meio de observação in loco, registro fotográfico, como também, por meio das entrevistas mencionadas anteriormente. Utilizou-se a técnica de observação direta (Appolinário, 2006) consistindo na observação e registro livre dos fenômenos observados em campo, com menor ou maior grau de envolvimento, respectivamente para um melhor entendimento.

Os dados etnobotânicos foram coletados logo após a aprovação do projeto de pesquisa no Comitê de Ética e Pesquisa (CEP) da Universidade Federal do Piauí, por meio do CAAE nº 0425.0.045.000-10, seguindo as normas definidas, inclusive na solicitação da assinatura dos entrevistados, conforme o Termo de Consentimento Livre e Esclarecido (TCLE). Com os entrevistados considerados não escolarizados recolheu-se a digital.

Por meio da técnica de turnê-guiada (Bernard, 1988), no qual os informantes foram ao campo ou aos quintais das residências em busca das amostras botânicas citadas nas entrevistas ou lembradas pelos mesmos no local de coleta. Essas coletas de amostras botânicas férteis seguiram a metodologia usual preconizada por Mori et al. (1989). Durante as coletas foram anotados no caderno de campo informações sobre as plantas, como: porte e altura da planta, cores e aromas das estruturas da planta, presença de látex ou exsudato, e quaisquer 
outras informações que podem ser perdidas no processamento da amostra ou que não sejam possíveis de observar na exsicata produzida a partir do material amostrado.

A identificação das amostras botânicas coletadas foi obtida por meio de consultas a literatura especializada, utilização de chaves de identificação, comparações morfológicas com exsicatas já identificadas no Herbário Graziela Barroso (TEPB) da Universidade Federal do Piauí (UFPI) e envio de material a especialistas onde, todo o material testemunho foi incorporado no TEPB, com número de tombo do 28.220 ao 28.262. Não foram coletadas as plantas compradas em feiras e comércios locais. A classificação das famílias botânicas baseou-se no APG IV (2016) e a atualização nomenclatural foi conferida através das bases de dados MOBOT (2016) e da Flora do Brasil on line (2016).

As espécies indicadas como úteis foram agrupadas em categorias de uso. A classificação do status nativa e exótica foi realizada com base na Flora do Brasil on line (2016), entretanto consideraram-se no estudo as espécies subespontâneas como exóticas.

Para os dados quantitativos, foi calculado Valor de Uso atribuído às espécies, aplicando-se a fórmula proposta por Phillips e Gentry (1993a; b) e Phillips et al. (1994), modificada por Rossato (1996), onde: VU = $\Sigma \mathrm{U} / \mathrm{n}(\mathrm{VU}=$ valor de uso; $\mathrm{U}=$ número de citações (ou uso) da espécie por informante e $\mathrm{n}=$ número total de informantes). Para verificar a significância das plantas usadas conforme idade e gênero dos informantes foi calculado o teste de Friedman (5\% de significância) (Vieira, 2003). As comparações entre a distribuição do conhecimento conforme gênero e idade dos informantes foram feitas com a utilização do teste Qui-quadrado de comparação de várias proporções (Vieira, 2003). Ambos foram calculados com auxílio do software BioEstat, versão 5.0 (Ayres et al. 2007).

\section{Resultados E Discussão}

Os assentados e agregados têm como base econômica a agricultura, onde grande parte é consumida pela família, e uma pequena escala é comercializada nas feiras livres dos municípios de São Miguel do Tapuio/PI e Novo Oriente/CE. O complemento da base econômica constitui os benefícios concedidos pelo Governo: aposentadorias e/ou bolsa-família. Fato também observado por Vieira et al. (2008) em uma comunidade quilombola localizado no mesmo município. A produção agrícola dos núcleos investigados é familiar, onde os homens e mulheres iniciam suas atividades desde cedo, com idade entre oito a dez anos, não havendo diferenciação de gênero para realização das tarefas do campo. Quando a produção demanda mais pessoas, realizam contrato com parentes e vizinhos, com pagamento feito por troca dos produtos gerados.

As 120 espécies indicadas pelos informantes nas entrevistas foram alocadas em dez categorias de uso: alimentícia, medicinal, construção, ornamental, forrageira, mágico-religiosa, artesanal, veterinária, cosmético e produção energética. Levando-se em consideração as 1.076 indicações citadas, as categorias de uso que se sobressaíram foram medicinais (512 citações); alimentícia (331) e construção (112), em comparação com produção energética (48); forrageira (23); veterinária (14); ornamental (13); mágico-religiosa (12); artesanal (6) e cosmético (5) (Figura 2). Os resultados observados na categoria medicinal evidenciaram que as plantas constituem um forte elemento na cultura local para o tratamento de sinais e sintomas de doenças, devido ao elevado número de citações, em consonância com os dados encontrados por Rossato et al. (1999), Albuquerque e Andrade (2002b), Rocha et al. (2002) Torres et al. (2009); Lopes e Lobão (2013); Duarte e Pasa (2015) e David 
e Pasa (2016) para o Brasil, como também nos trabalhos desenvolvidos em outros países por Reys-Garcia et al. (2005); Camou-Guerrero et al. (2008); Choudhary et al. (2008) e Ubom (2010).

Figura 2- Famílias botânicas mais representativas em número de espécies indicadas pelos informantes dos núcleos urbanos Juazeiro e Umburana do PA Saco do Juazeiro, São Miguel do Tapuio/PI

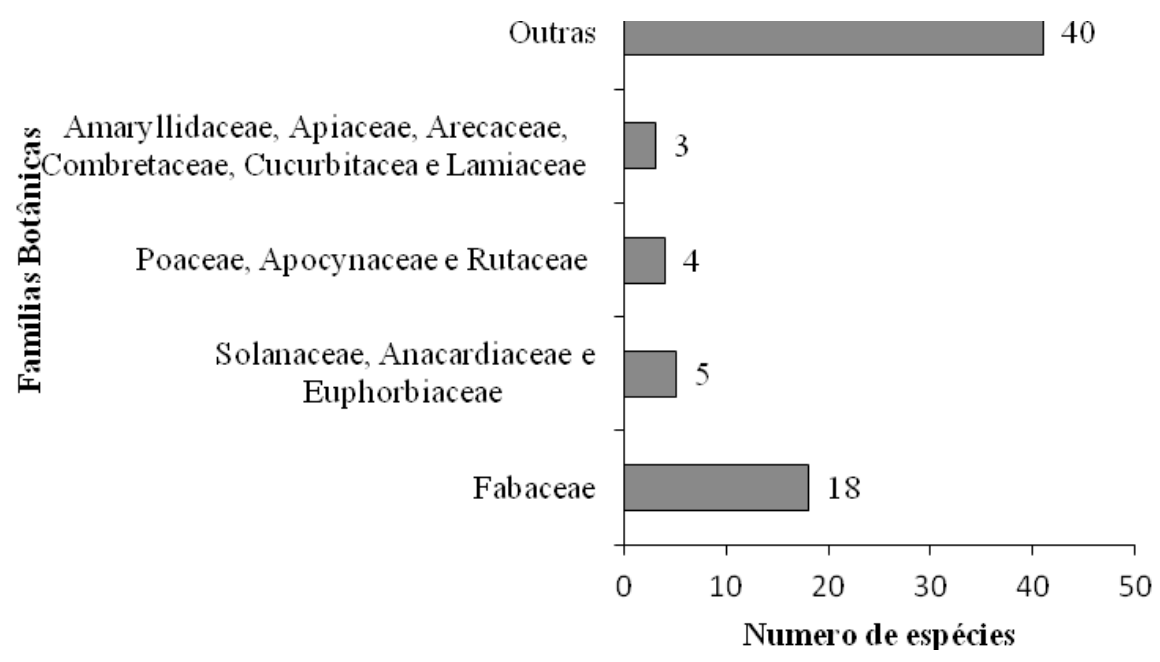

As espécies referidas apresentam-se como ervas, subarbustos, arbustos, árvores elianas, com a predominância de plantas herbáceas (36\%) e arbóreas (29\%) (Tabela 1). Pinto et al. (2006), Pilla et al. (2006) e Carniello et al. (2010) também encontraram plantas herbáceas e arbóreas como mais utilizadas.

O percentual de espécies nativas e exóticas foi de 55\% a 45\%, respectivamente, coletadas na vegetação nativa e nos quintais. Nestes últimos, é comum observar a presença de espécies nativas, observação também referida por Rico-Gray et al. (1990), Nair (2004) e Albuquerque et al. (2005). Dessa forma, predominaram espécies nativas, resultado divergente dos apresentados por Amaral e Guarim Neto (2008) em quintais da cidade de Rosário Oeste no Mato Grosso, Souza e Felfili (2006) na região do Alto Paraíso de Góias-GO e por Carniello et al. (2010) em quintais urbanos de Mirassol D'Oeste-MT.

Do número total de plantas identificadas, 57 foram citadas para exclusivamente uma categoria de uso, como se segue: 24 espécies usadas apenas como medicinal; 17 como alimentícia; 07 como ornamental; 03 como forrageira e mágico-religiosa; 02 como construção e uma como artesanal. Das 24 espécies citadas para duas categorias, medicinal/alimentícia se sobressaíram com 11 espécies. As outras se dividem nas demais categorias. O número de espécies medicinais, bem como, de alimentares é coeso com a realidade do grupo pesquisado, pois a população encontra-se inserida em ambiente rural relativamente distante dos grandes centros comerciais, realizando práticas agrícolas propriamente ditas. A categoria medicinal, em alguns trabalhos realizados como os de Begossi et al. (1993), Rossato et al. (1999), Amorozo (2002), Di Stasi et al. (2002), Silva e Albuquerque (2005), Vendruscolo e Mentz (2006), Camou-Guerrero (2008), Franco e Barros (2008), Chaves e Barros (2008) e Vieira et al. (2008) também demonstraram ser a mais representada em número de espécies.

As espécies encontram-se distribuídas em 54 famílias botânicas, sendo três identificadas ao nível de gênero. Destas, as que mais se destacaram em número de espécies foram Fabaceae (18), Solanaceae / Anacardiaceae / Euphorbiaceae (5 cada), seguidas de Poaceae / Apocynaceae / Rutaceae (4) e Amaryllidaceae / Apiaceae / Arecaceae / Combretaceae / Cucurbitaceae / Lamiaceae (3 cada). Estas 13 famílias somam 63 espécies, significando 52,5\% (Figura 3). Para a família mais representativa dados semelhantes foram apresentados em estudos realizados por Azevedo e Silva (2006), Botrel et al. (2006) e Franco e Barros (2006). 
Tabela 1- Lista de espécies úteis citadas pelos assentados dos núcleos urbanos Juazeiro e Umburana do PA Saco do Juazeiro, São Miguel do Tapuio, Piauí, Brasil. Convenções: NV: Nome Vernacular. Hb = Hábitos: her $=$ erva; arb $=$ arbusto; $\mathrm{sub}=$ subarbusto; arv $=$ árvore e lia $=$ liana, $\mathrm{St}=$ Satus: $\mathrm{n}=$ nativa, $\mathrm{e}=$ exótica. Cat. $\mathrm{U}=$ Categoria de Uso: $\mathrm{a}$ $=$ medicinal $; \mathrm{b}=$ artesanal $\mathrm{c}=$ alimentícia $; \mathrm{d}=$ ornamental $\mathrm{e}=$ construção $\mathrm{f}=$ forrageira $; \mathrm{g}=$ mágico-religiosa; $\mathrm{h}=$ produção energética; $i=$ cosmético e $j=$ veterinária. VU = Valor de Uso. NC (Número de Coletor) EB (Ethyênne Bastos) e PA (Patrícia Alves). il = Identificado no local, não coletada; $\mathrm{c}=$ plantas compradas.

\begin{tabular}{|c|c|c|c|c|c|c|}
\hline Família/Espécie & NV & $\mathbf{H b}$ & St & Cat.U & VU & NC \\
\hline \multicolumn{7}{|l|}{ Acanthaceae } \\
\hline Justicia pectoralis var. stenophylla Leonard & Trevo & her & $\mathrm{n}$ & $g$ & 0,09 & c \\
\hline \multicolumn{7}{|l|}{ Amaranthaceae } \\
\hline Chenopodium ambrosioides L. & Mastruz & her & $\mathrm{n}$ & a & 0,26 & EB 84 \\
\hline \multicolumn{7}{|l|}{ Amaryllidaceae } \\
\hline Allium cepa $\mathrm{L}$. & Cebola & her & $\mathrm{e}$ & $\mathrm{a}, \mathrm{c}$ & 0,04 & il \\
\hline A. sativum $\mathrm{L}$. & Alho & her & $\mathrm{e}$ & a & 0,07 & c \\
\hline A. schoenoprasum $\mathrm{L}$. & Cheiro-verde & her & $\mathrm{e}$ & c & 0,02 & il \\
\hline \multicolumn{7}{|l|}{ Anacardiaceae } \\
\hline Anacardium occidentale L. & Caju & $\operatorname{arv}$ & $\mathrm{n}$ & $a, c$ & 0,09 & $\mathrm{~EB} 69$ \\
\hline Mangifera indica L. & Manga & $\operatorname{arv}$ & $\mathrm{e}$ & c & 0,02 & il \\
\hline Myracrodruon urundewva Allemão & Aroeira-mansa & arv & $\mathrm{n}$ & $a, j$ & 0,05 & EB 100 \\
\hline Spondias purpurea L. & Siriguela & $\operatorname{arv}$ & $\mathrm{e}$ & c & 0,02 & il \\
\hline S. tuberosa Arruda & Imbu & $\operatorname{arv}$ & $\mathrm{n}$ & $\mathrm{a}, \mathrm{c}$ & 0,04 & il \\
\hline \multicolumn{7}{|l|}{ Annonaceae } \\
\hline Annona squamosa $\mathrm{L}$. & Ata & arb & $\mathrm{e}$ & $\mathrm{a}, \mathrm{c}$ & 0,04 & il \\
\hline A.muricata $\mathrm{L}$. & Graviola & arv & $\mathrm{e}$ & c & 0,02 & il \\
\hline \multicolumn{7}{|l|}{ Apiaceae } \\
\hline Anethum graveolens $\mathrm{L}$. & Endro & her & $\mathrm{e}$ & a & 0,02 & $\mathrm{c}$ \\
\hline Coriandrum sativum $\mathrm{L}$. & Coentro & her & $\mathrm{e}$ & $\mathrm{a}, \mathrm{c}$ & 0,09 & il \\
\hline Foeniculum vulgare Mill. & Erva-doce & her & $\mathrm{e}$ & a & 0,09 & c \\
\hline \multicolumn{7}{|l|}{ Apocynaceae } \\
\hline Calothropis procera (Aiton) W.T. Aiton & Ciúme & arb & $\mathrm{e}$ & $\mathrm{b}$ & 0,02 & EB 67 \\
\hline $\begin{array}{l}\text { Catharanthus roseus (L.) G. Don } \\
\text { Himatanthus drasticus (Mart.) Plumel } \\
\text { Plumeria rubra L }\end{array}$ & $\begin{array}{l}\text { Boa-noite } \\
\text { Janaguba } \\
\text { Jasmim }\end{array}$ & $\begin{array}{l}\text { her } \\
\text { arb } \\
\text { arb }\end{array}$ & $\begin{array}{l}\mathrm{e} \\
\mathrm{n} \\
\mathrm{e}\end{array}$ & $\begin{array}{l}\mathrm{d} \\
\mathrm{a} \\
\mathrm{d}\end{array}$ & $\begin{array}{l}0,02 \\
0,04 \\
0,02\end{array}$ & $\begin{array}{l}\text { EB } 78 \\
\text { EB } 101 \\
\text { EB } 88\end{array}$ \\
\hline \multicolumn{7}{|l|}{ Araceae } \\
\hline Dieffenbachia seguine (Jacq.) Schott & $\begin{array}{l}\text { Comigo- } \\
\text { ninguém-pode }\end{array}$ & her & $\mathrm{n}$ & $\mathrm{d}$ & 0,02 & EB 74 \\
\hline \multicolumn{7}{|l|}{ Arecaceae } \\
\hline Cocos nucifera $\mathrm{L}$. & Coco & $\operatorname{arv}$ & $\mathrm{e}$ & $\mathrm{c}$ & 0,02 & il \\
\hline Mauritia flexuosa L. f. & Buriti & $\operatorname{arv}$ & $\mathrm{n}$ & a & 0,02 & il \\
\hline Copernicia prunifera (Mill.) H.E. Moore & Carnaúba & $\operatorname{arv}$ & $\mathrm{n}$ & $\mathrm{a}, \mathrm{b}, \mathrm{e}$ & 0,05 & il \\
\hline \multicolumn{7}{|l|}{ Asparagaceae } \\
\hline Sansevieria trifasciata Prain & São-jorge & her & e & $\mathrm{d}$ & 0,02 & EB 81 \\
\hline Sansevieria sp. & Santa-barbara & her & $\mathrm{e}$ & $\mathrm{d}$ & 0,02 & EB 82 \\
\hline
\end{tabular}




\begin{tabular}{|c|c|c|c|c|c|c|}
\hline \multicolumn{7}{|l|}{ Asteraceae } \\
\hline Wedelia villosa Gardn. & Camará & sub & $\mathrm{n}$ & a & 0,04 & EB 99 \\
\hline Lactuca sativa $L$. & Alface & her & e & a & 0,02 & il \\
\hline \multicolumn{7}{|l|}{ Bignoniaceae } \\
\hline Handroanthus impetiginosus Mattos. & Pau-d'arco- roxo & $\operatorname{arv}$ & $\mathrm{n}$ & a,e & 0,14 & EB 55 \\
\hline \multicolumn{7}{|l|}{ Burseraceae } \\
\hline Commiphora leptophloeos (Mart.) Gillet & $\begin{array}{l}\text { Umburana-de- } \\
\text { espinho }\end{array}$ & $\operatorname{arv}$ & $\mathrm{n}$ & a & 0,02 & $\mathrm{~EB} 62$ \\
\hline \multicolumn{7}{|l|}{ Bixaceae } \\
\hline Bixa orellana $\mathrm{L}$. & Urucum & arb & $\mathrm{n}$ & c & 0,02 & EB 71 \\
\hline \multicolumn{7}{|l|}{ Brassicaceae } \\
\hline Nasturtium officinale (W. T. Aiton) Royen & Agrião & her & $\mathrm{e}$ & a & 0,02 & il \\
\hline \multicolumn{7}{|l|}{ Bromeliaceae } \\
\hline Ananas comosus (L.) Merr. & Abacaxi & her & $\mathrm{n}$ & $\mathrm{c}$ & 0,02 & il \\
\hline Bromelia laciniosa Mart. ex Schult & Macambira & her & $\mathrm{n}$ & $\mathrm{f}$ & 0,02 & EB 61 \\
\hline \multicolumn{7}{|l|}{ Boraginaceae } \\
\hline Cordia tricotoma Vell. & Frejorge & $\operatorname{arv}$ & $\mathrm{n}$ & e & 0,02 & EB 85 \\
\hline \multicolumn{7}{|l|}{ Cactaceae } \\
\hline Opuntia ficus-indica (L.) P. Mill. & Palma & her & $\mathrm{e}$ & $\mathrm{a}, \mathrm{d}, \mathrm{f}$ & 0,05 & il \\
\hline \multicolumn{7}{|l|}{ Cannabaceae } \\
\hline Cannabis sativa $\mathrm{L}$. & Maconha & her & $\mathrm{e}$ & a & 0,05 & $*$ \\
\hline \multicolumn{7}{|l|}{ Caricaceae } \\
\hline Carica papaya L. & Mamão & arb & $\mathrm{e}$ & c & 0,02 & il \\
\hline \multicolumn{7}{|l|}{ Capparaceae } \\
\hline Cynophallas flexuosa (L.) J.Presl & Feijão-brabo & arb & $\mathrm{n}$ & $a, j$ & 0,02 & EB 93 \\
\hline Tarenayae spinosa (Jacq.) Raf. & Muçambê & sub & $\mathrm{n}$ & a & 0,05 & EB 58 \\
\hline \multicolumn{7}{|l|}{ Cochlospermaceae } \\
\hline Cochlospermum vitifolium Spreng. & Algodão-bravo & arb & $\mathrm{n}$ & $\mathrm{d}$ & 0,02 & il \\
\hline \multicolumn{7}{|l|}{ Combretaceae } \\
\hline Combretum leprosum Mart. & Mofumbo & arb & $\mathrm{n}$ & a & 0,19 & PA 40 \\
\hline Terminalia catappa $\mathrm{L}$. & Castanhola & $\operatorname{arv}$ & $\mathrm{e}$ & a & 0,02 & EB 106 \\
\hline T. fagifolia Mart. & Chapada & $\operatorname{arv}$ & $\mathrm{n}$ & $\mathrm{a}, \mathrm{e}, \mathrm{h}$ & 0,12 & PA 25 \\
\hline \multicolumn{7}{|l|}{ Convolvulaceae } \\
\hline Ipomoea SP & Jitirana & lia & $\mathrm{n}$ & $\mathrm{d}$ & 0,02 & EB 56 \\
\hline \multicolumn{7}{|l|}{ Cucurbitaceae } \\
\hline Citrullus vulgaris Schrad. & Melancia & her & e & c & 0,02 & il \\
\hline Cucurbita pepo L. & Abóbora & her & $\mathrm{e}$ & $\mathrm{c}$ & 0,02 & EB 79 \\
\hline Momordica charantia L. & $\begin{array}{l}\text { Melão-de-são- } \\
\text { caetano }\end{array}$ & her & $\mathrm{n}$ & a & 0,02 & EB 57 \\
\hline \multicolumn{7}{|l|}{ Euphorbiaceae } \\
\hline Croton blanchetianus Baill & Mameleiro & sub & $\mathrm{n}$ & $\mathrm{a}, \mathrm{e}$ & 0,14 & PA 41 \\
\hline C. grawioides Baill & Canela-braba & sub & $\mathrm{n}$ & $\mathrm{a}, \mathrm{c}, \mathrm{h}$ & 0,14 & EB 102 \\
\hline Jatropha gossypiifolia L. & Pinhão-roxo & arb & $\mathrm{n}$ & $\mathrm{d}, \mathrm{g}$ & 0,07 & PA 54 \\
\hline Manihot esculenta Crantz & Mandioca & her & $\mathrm{n}$ & $\mathrm{c}$ & 0,02 & il \\
\hline
\end{tabular}


Ricinus communis $\mathrm{L}$.

\section{Fabaceae}

\section{Caesalpinioideae}

Baubinia dubia G.Don.

B. guianensis Aubl

Copaifera luetzelburgii Harms

Hymenaea courbaril L.

Libidibia ferrea (Mart. ex Tul.) L.P.Queiroz Martiodendron mediterraneum (Mart. ex Benth.)

Koeppen

Poincianella bracteosa (Tul.) L.P.Queiroz

Tamarindus indica $\mathrm{L}$.

\section{Mimosoideae}

Anadenanthera colubrina (Vell.) Brenan

Leucaena leucocephala (Lam.) de Wit

Mimosa tenuiflora (Wild.) Poir.

Piptadenia stipulacea (Benth.) Ducke

Pityrocarpa moniliformis (Benth.) Luckow \&

R.W.Jobson

Senegalia polyphylla (DC.) Britton \& Rose

Vachellia farnesiana (L.) Wight \& Arn

\section{Papilionoideae}

Amburana cearensis (Allemao) A.C.Sm

Phaseolus vulgaris $\mathrm{L}$.

Pterodon abruptus (Moric.) Benth.

\section{Iridaceae}

Cipura paludosa Aubl.

\section{Lamiaceae}

Ocimum americanum $\mathrm{L}$.

Plectranthus amboinicus (Lour.) Spreng.

P. barbatus Andr.

\section{Lauraceae}

Persea americana Mill.

\section{Lythraceae}

Punica granatum L.

Malvaceae

Malva sylvestris L.

\section{Malpighiaceae}

Malpighia glabra L.

Melastomataceae

Miconia albicans (Sw.) Triana

\section{Meliaceae}

Cedrela odorata L.

Moraceae

Brosimun gaudichaudii Trécul.

\section{Musaceae}

Mamona

arb

n

0,02

EB 68

\begin{tabular}{|c|c|c|c|c|c|}
\hline Mororó & arb & $\mathrm{n}$ & e & 0,02 & EB 60 \\
\hline Mangirioba & arb & $\mathrm{n}$ & $\mathrm{a}$ & 0,02 & PA 45 \\
\hline Podói & arv & $\mathrm{n}$ & $\mathrm{a}$ & 0,11 & PA 21 \\
\hline Jatobá & arv & $\mathrm{n}$ & $\mathrm{a}$ & 0,09 & EB 63 \\
\hline Jucá & arv & $\mathrm{n}$ & $\mathrm{a}, \mathrm{f}, \mathrm{j}$ & 0,19 & EB 52 \\
\hline Pau-pedra & arv & $\mathrm{n}$ & $\mathrm{a}$ & 0,02 & EB 10 \\
\hline Catingueira & arb & $\mathrm{n}$ & $\mathrm{a}, \mathrm{h}$ & 0,11 & PA 46 \\
\hline Tamarindo & arv & e & $\mathrm{a}, \mathrm{c}$ & 0,04 & il \\
\hline Angico-preto & arv & $\mathrm{n}$ & $\mathrm{a}, \mathrm{e}, \mathrm{h}$ & 0,14 & EB 91 \\
\hline Leucena & arv & e & $\mathrm{f}$ & 0,02 & EB 70 \\
\hline Jurema-preta & arv & $\mathrm{n}$ & $\mathrm{a}, \mathrm{e}, \mathrm{h}$ & 0,09 & $\mathrm{~EB}$ \\
\hline Jurema-branca & arv & $\mathrm{n}$ & $\mathrm{h}$ & 0,02 & EB 96 \\
\hline Rama-de-bezerra & arv & $\mathrm{n}$ & $\mathrm{a}, \mathrm{e}, \mathrm{h}$ & 0,08 & EB 64 \\
\hline Espinheiro & arb & $\mathrm{n}$ & $\mathrm{j}$ & 0,02 & $\mathrm{~EB}$ \\
\hline Coronha & arb & $\mathrm{n}$ & $a, g$ & 0,11 & $\mathrm{~EB}$ \\
\hline
\end{tabular}

Umburana-de-

cheiro

arv

0,11

EB 104

Feijão

Amarelão

her

0,04

il

arv

0,04

EB 90

Cebola-da-índia

her

Manjericão

her

her

Malva-santa

Boldo

her

Abacate

$\operatorname{arv}$

il

Romã

arb

Malva/Malva-doreino

her

Acerola

arb

Canelinha

arb

n

a

0,02

EB 97

Cedro

arv

n

0,02

EB 86

arv

n

0,07

EB 94 
Musa paradisiaca L.

Myrtaceae

Eucalyptus SP

Psidium guajava L.

Nyctaginaceae

Guapira venosa (Choisy) Lundell

\section{Olacaceae}

Ximenia americana $\mathrm{L}$.

\section{Passifloraceae}

Passiflora edulis Sims.

\section{Phyllanthaceae}

Phyllanthus niruri L.

Phytolaccaceae

Petiveria alliacea $\mathrm{L}$.

\section{Portulacaceae}

Portulaca grandiflora Hook.

\section{Poaceae}

Cymbopogon citratus (DC.) Stapf

Pennisetum purpureum Schumach.

Saccharum officinarum $\mathrm{L}$.

Zea mays $\mathrm{L}$.

\section{Rhamnaceae}

Ziziphus joazeiro Mart .

\section{Rutaceae}

Citrus $\mathrm{x}$ aurantium $\mathrm{L}$.

C. x limon (L.) Osbeck

C. reticulata Blanco

Ruta graveolens L.

\section{Rubiaceae}

Genipa americana L.

Morinda citrifolia $\mathrm{L}$.

\section{Sapindaceae}

Cardiospermum halicacabum L.

\section{Solanaceae}

Capsicum annum $\mathrm{L}$.

C. frutescens $\mathrm{L}$.

C. chinense Jacq.

Solanum paniculatum L.

\section{Verbenaceae}

Lippia alba (Mill.) N.E.Br.

L. gracillis Humb., Bonpl. \& Kunth.
Lycopersicon esculentum Mill.
Banana

her

Eucalipto

Goiaba

João-mole

Ameixa

Maracujá

Quebra-pedra

Tipi

Nove-hora

Capim-santo

Capim-elefante

Cana-de-açúcar

Milho

Juazeiro

Laranja

Limão

Tangerina

Arruda

Jenipapo

Noni

Laça-vaqueiro

Pimentão

Pimenta-

malagueta

cheiro

Tomate

Jurubeba

Erva-cidreira

Alecrim

arv

arv

arv

arb

lia

her

her

her

her

her

her

her

her

arv

arb

arb

arb

her

arv

arb

lia

sub

sub

sub

her

arb

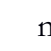

n

$\mathrm{a}, \mathrm{c}, \mathrm{j}$

0,23

PA 37

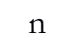

$$
\text { n }
$$

$$
\text { e }
$$

$$
\text { n }
$$

e

$a, c, g$

0,14

EB 83

(

$$
\mathrm{f}
$$

0,02

EB 65

,02

EB 66$$
\text { n }
$$

n$$
\mathrm{c}, \mathrm{f}, \mathrm{i}
$$

0,05

PA 86

(1)

e

$a, c$

0,04

0,11

il

a.c,j

0,02

0,14

EB 80

0,02

il

n

0,07

il

Violaceae 


\begin{tabular}{lllllll}
\hline $\begin{array}{l}\text { Hybanthus ipepacuanba Baill. } \\
\text { Xanthorrhoeaceae }\end{array}$ & Papacônia & her & $\mathrm{n}$ & $\mathrm{a}$ & 0,04 & il \\
$\begin{array}{l}\text { Aloe vera (L.) Burm.f. } \\
\text { Zingiberaceae }\end{array}$ & Babosa & her & e & a,g,i & 0,28 & il \\
Alpinia nutans (L.) Rosc. & Jardineira & her & e & g & 0,02 & EB 75 \\
\hline
\end{tabular}

* Planta no passado era cultivada para o consumo e utilizada como medicamento.

Quanto às espécies com maior frequência de citações, destacam-se: Croton blanchetianus, Anadenanthera colubrina, Ximenia americana, Aloe vera; Anacardium occidentale, Psidium guajava, Lippia alba, Mangifera indica, Handroanthus impetiginosus, Combretum leprosum, Anadenanthera colubrina, Spondias purpurea e Cocos nucifera. A maioria é utilizada como medicinal, sendo que a $P$. guajava e o $A$. occidentale também usadas como alimentícia; $C$. blanchetianus e $A$. colubrina foram citadas como combustível.

Figura 3 - Percentual de citações por categorias de uso das plantas utilizadas pelos moradores dos núcleos urbanos Juazeiro e Umburana do PA Saco do Juazeiro, São Miguel do Tapuio/PI

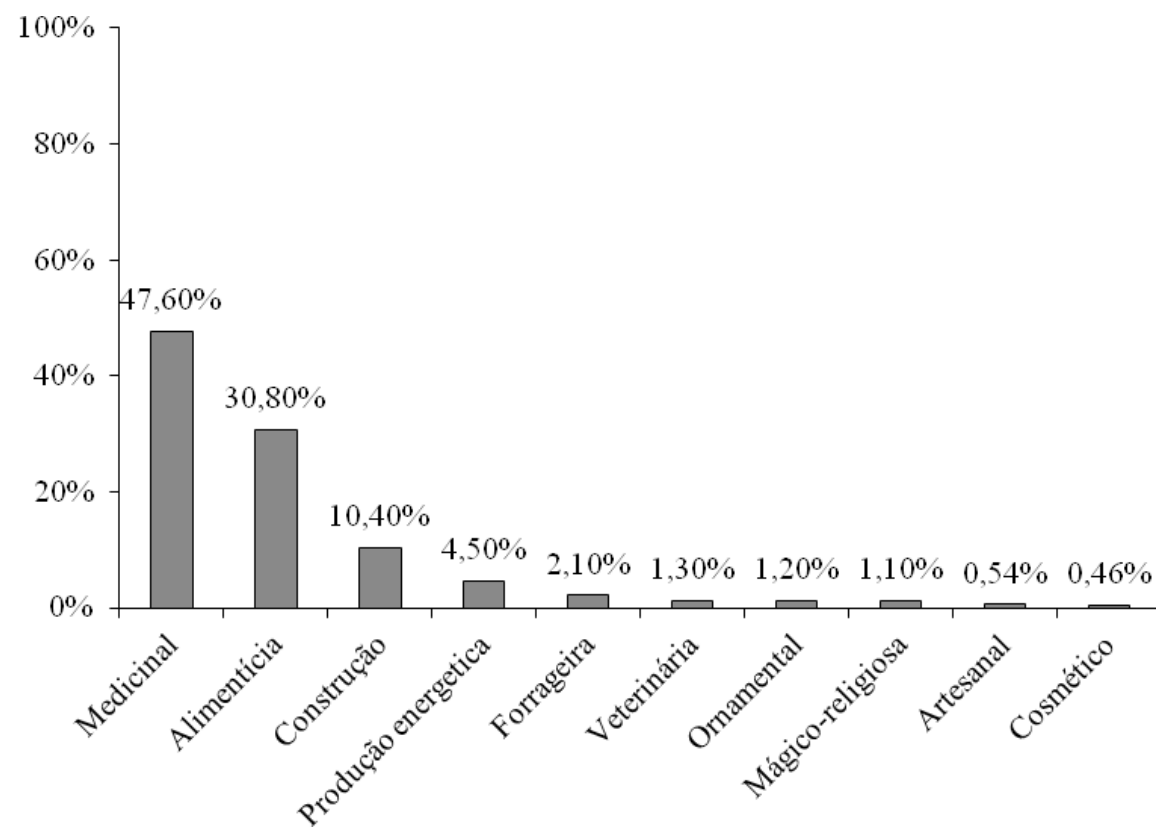

As categorias de Uso

Medicinal - a tradição de usar plantas para o combate aos problemas corriqueiros é algo que faz parte da cultura dos núcleos estudados. Em relação às 65 espécies indicadas como medicinais, as cascas foram às partes mais citadas para a elaboração dos remédios (39,2\%), seguidas das folhas $(37,6 \%)$, sementes $(7,8 \%)$, raízes $(5,6 \%)$, flores (3,6\%), frutos (3,5\%) e resinas (2,5\%). Neste ponto, os dados deste trabalho diferem dos dados obtidos por Agra et al. (2007) no Cariri/ PB; De-la-Cruz et al. (2007) nos Andes peruanos e Pasa (2011) na comunidade Jardim, Cuiabá/MT, que verificaram a predominância das folhas como parte mais utilizada. Albuquerque e Andrade (2002a), Coutinho (2002) e Alves et al. (2007) também citam as cascas como recurso mais utilizado, por estarem disponíveis o ano todo, devido a caducifolia das folhas na época seca. Para as formas de preparo informadas pelos moradores sobressaíram os chás: infusão e decocto (48,6\%), seguidas de garrafada (18,9\%), xarope (16,3\%), maceração (9,8\%), pó (3,8\%), banho $(1,5 \%)$, infusão em álcool $(0,6 \%)$ e in natura $(0,4 \%)$. Resultados semelhantes foram obtidos por Pinto et al. (2006) nas comunidades de Marambaia e 
Camboinha em Itacaré/BA e por Monteles e Pinheiro (2007) em um quilombo maranhense. Nas comunidades rurais, o modo de preparo dos remédios utilizados nos procedimentos terapêuticos também apresenta uso combinado de plantas para tratamentos variados, sendo utilizados também outros ingredientes, como vinho, leite e açúcar entre outros. Ximenia americana mostrou-se a mais versátil entre as medicinais, sendo utilizada no trato de inflamações uterinas, como cicatrizante e para gripe. Caratér também observado por Chaves e Barros (2008) em comunidade localizada na APA na Serra da Ibiapaba/PI.

Alimentícia - nesta categoria foram incluídas 39 espécies. Em termos de atividade agrícola, as culturas do feijão (Phaseolus vulgaris) e do milho (Zea mays) predominaram. Dentre as espécies citadas, mais da metade são frutíferas (57,5\%), seguindo-se as verduras e legumes $(27,5 \%)$ e temperos (15\%). Dados similares foram reportados por Valadão et al. (2006) em um assentamento rural no municipio de Cordeirópolis/SP. Observou-se que a maioria das espécies são exóticas e cultivadas principalmente nos quintais. Pode-se mencionar: Allium cepa, Coriandrum sativum e Lycopersicon esculentum. Em comparação ao estudo realizado por Vieira et al. (2008), apenas $A$. cepa foi à espécie em comum com as mencionadas nos núcleos urbanos. Já para as nativas destacam-se Psidium guajava, Spondias tuberosa e Anacardium occidentale, sendo esta a espécie também citada nos trabalhos de FonsecaKruel e Peixoto (2004) na RESEX marinha de Arraial do Cabo/RJ e Torres et al. (2009) em comunidades de uma APA no Rio Grande do Norte.

Construção - representada por 10 espécies alocadas em 07 famílias botânicas. A família que mais contribuiu com número de espécies foi a Fabaceae (5), as demais foram representadas por apenas 01 espécie. As espécies referidas são utilizadas na construção de casas, cercas e cabos de ferramentas agrícolas (enxada, foice e machado). Nessa categoria, observou-se que o status das espécies foi exclusivamente nativa. Algumas delas foram citadas de forma exclusiva, como por exemplos: Croton blanchetianus, que obteve maior número de citações, indicada especialmente na confecção de cercas. Copernicia prunifera foi citada para construção de casas, sendo aproveitada como linhas, caibros e ripas. Vieira et al. (2008) também a referiu como uma das espécies preferidas pelos quilombolas. Chaves e Barros (2008) mencionam a espécie preferencialmente para construção de casas (linha). Na confecção dos cabos das ferramentas agrícolas, Handroanthus impetiginosus foi à espécie mais citada e elencada, sendo referida como de excelente qualidade, muito dura e resistente. Em termos gerais, essa categoria é uma das mais citadas em estudos etnobotânicos, podendo destacar os trabalhos de Rodrigues et al. (2002) em Luminárias/MG, que observaram a utilização na confecção de gamelas, colheres de pau e carro de bois. A população pesquisada ressalta que o período do corte da planta pode intervir na qualidade da madeira e para ter uma maior resistência, sem rachaduras e nem caruche, deve ser extraída na lua minguante. Pinheiro et al. (2005) estudaram os usos de subsistência de espécies vegetais na região da baixada maranhense, citando como princiapis usos: cercas, esteios, fibras para amarrilho, portas e cofos. Hanazaki et al. (2006) ao realizarem estudos junto aos populares rurais próximos ao Parque Estadual Carlos Botelho/SP, citam a categoria com 24\% do total das espécies úteis, sendo utilizadas nas construções de casas, canoas, dentre outros.

Produção energética - as espécies são empregadas exclusivamente como combustível em forma de carvão ou lenha, sendo representada por sete espécies, ou seja, 5,8\% do total das espécies reportadas. Apresentam-se como plantas mais citada para este uso: Anadenanthera colubrina, Pityrocarpa moniliformis, Mimosa tenuiflora, Poincianella bracteosa e Pterodon abruptus. Nos núcleos pesquisados, a maior parte das residências dispõe de fogão a gás, no 
entanto, os entrevistados relataram que preferem os fornos a lenha para o preparo dos alimentos, pois segundo eles a comida preparada neles é mais gostosa. Observação semelhante foi referida por Rodrigues et al. (2002) que estudaram comunidades no município de Luminária/MG. Observou-se que das espécies citadas nessa categoria, quatro são também empregadas na categoria construção e embora possuam tão poucos representantes citados pelos informantes, essa é uma das categorias que possui o maior impacto sobre a vegetação local.

Forrageira - foram indicadas 09 espécies como forrageiras, representando 7,5\% do total. Essa categoria atingiu a quinta colocação em número de citações (23), provavelmente pelo modo local da criação extensiva de bovinos, suínos, caprinos, ovinos e avicultura de uma boa parte dos moradores. Observou-se que as lembranças sobre essas plantas forrageiras, estavam ligadas ao período de grande estiagem. Nestes períodos, para reforçar a alimentação dos animais, a Leucaena leucocephala e Libidibia ferrea foram às espécies mais citadas, tornando-as principal forma de sustento dos rebanhos. Obtiveram ainda citações, as seguintes espécies: Saccharum officinarum, Pennisetum purpureum, Phaseolus vulgaris, Ziziphus joazeiro, Bromelia laciniosa e Zea mays. Batista et al. (2005) ao estudarem as espécies da flora em uma área de caatinga em Serra Talhada/PE apresentaram em seus resultados 03 espécies forrageiras, e entre essas citou a Ziziphus joazeiro, indicada também nesse estudo para a mesma finalidade. Ressalta-se que o consumo das espécies pelos animais é natural, ou seja, diretamente no ambiente e o acesso acontece no pasto e no entorno das residências, não ocorrendo armazenamento das partes consumidas (folhas e flores). As famílias Fabaceae e Poaceae apresentaram maior representatividade de espécies para essa categoria, com 33\% cada. Destaca-se que nas pesquisas realizadas por Lemos (2001), Ferraz et al. (2006). Oliveira et al. (2009) e Vieira et al. (2008), houve também maior representatividade dessas famílias botânicas nesta categoria de uso.

Veterinária - essa categoria obteve 08 citações de espécies indicadas para uso terapêutico exclusivo das doenças em bovinos. Ximenia americana, Cynophallas flexuosa, Poincianella bracteosa, Libidibia ferrea e Solanum paniculatum foram as mais citadas. Essas mesmas espécies foram referidas por Marinho et al. (2007) no estudo sobre a utilização de plantas medicinais em medicina veterinária no município de Patos/PB. Em relação às partes vegetativas das plantas, utilizadas no preparo dos fitoterápicos, estas variaram de acordo com a planta. A forma de administração do medicamento, em geral, foi o uso oral e tópico, sendo utilizada a água para a obtenção da forma de maceração e chás (decocto ou infusão).

Ornamental - foram levantadas 11 espécies, utilizadas para ornamentar as residências, os velórios e para embelezar o jardim, como também para enfeitar as portas e janelas durante as comemorações de São Gonçalo. Catharanthus roseus, Lippia gracillis, Dieffenbachia picta, Ipomoea sp, Plumeria rubra, Portulaca grandiflora e Sansevieria trifasciata estão entre as espécies utilizadas nos núcleos. A citação de plantas ornamentais nos núcleos concentrouse mais nas mulheres $(84,6 \%)$, possivelmente por serem elas as responsáveis em manter os quintais e jardins, assim como afirmado por Aguiar (2009) e Sablayioles (2004).

Mágico-religiosa - representando apenas 8\%, nessa categoria foram incluídas 09 espécies. Estas foram citadas única e exclusivamente por mulheres. Foram indicadas no uso de rezas para doenças em crianças, benzeduras, afastar mau-olhado, quebrante em recém-nascido, trazer bons presságios, abrir os caminhos, entre 
outros. Dentre as citadas destacam-se a Ruta graveolens, que se apresentou como mais versátil, utilizada para benzeduras e afastar mau-olhado, fato este também relatado por Aguiar (2009); Jatropha gossypiifolia é comumente usada na frente das residências, como forma de espantar mau-olhado, prática também verificada por Vieira et al. (2008) em um quilombo na mesma região. Observou-se que para esta categoria, algumas espécies foram também referidas para o uso medicinal, alimentar e ornamental, como: Cymbopogon citratus, Capsicum frutescens e Petiveria alliacea, respectivamente.

Artesanal - consideraram-se as plantas de uso artesanal, as espécies que serviam para fabricação de utensílios domésticos. A representação foi dada por duas espécies, correspondendo a 1,8\% das plantas levantadas. Copernicia prunifera foi à espécie que obteve maior número de indicação de uso nesta categoria, em que suas palhas são aproveitadas para produção de vassouras, cofos, surrões, abanos e cestas. Essa prática artesanal é desenvolvida por uma única família do núcleo urbano Juazeiro, que perpassa entre gerações. Vale ressaltar, que esta prática não está ligada a principal atividade econômica do núcleo, sendo apenas um complemento da renda familiar. Evento contrário foi apresentado por Silva (2010) na comunidade Resolvido no cerrado piauiense, que produz vassouras com palha de C. prunifera favorecendo a comunidade economicamente, bem como, garantindo o uso sustentável dessa palmeira.

Cosmético - nessa categoria as 02 espécies citadas foram Ziæiphus joąeiro e Aloe vera. A primeira indicada para higiene bucal e a segunda para limpeza capilar. Dados semelhantes foram reportados por Oliveira (2009) em comunidades rurais do semiárido piauiense. A categoria cosmética foi indicada no núcleo urbano Umburana por apenas um entrevistado. Os trabalhos de Silva e Andrade (2005) em comunidades situadas na Região Metropolitana do Recife (RMR), Zona do Litoral-Mata de Pernambuco e de Boscolo e Vale (2008) em Quissamã/RJ, também apresentaram poucas citações para essa categoria.

\section{Valor de Uso das espécies}

O Valor de Uso (VU) mostra quais plantas são mais conhecidas e utilizadas pelos entrevistados naquele espaço e tempo. Para tentar minimizar o aumento das estimativas referentes ao VU, Stagegaar et al. (2002) citam que tal fato pode estar relacionado com os usos potenciais nunca realizados. Por isso, solicitou-se que os informantes citassem as espécies usadas e não apenas conhecidas.

Entre as espécies citadas pelos assentados dos núcleos urbanos Juazeiro e Umburana, as que obtiveram os maiores valores de uso foram: Aloe vera $(0,28)$; Chenopodium ambrosioides $(0,26)$ e Ximenia americana $(0,23)$, consideradas principalmente de grande potencial medicinal.

A babosa é uma planta muito requisitada pela população e teve seu uso associado às categorias medicinal, mágico-religiosa e cosmético. Dentro da categoria medicinal, as folhas são utilizadas no combate a gripe, má digestão, dor nos ossos, dor na coluna, dores em geral, próstata, cólicas menstruais, problemas do coração, gastrite, inflamação, verminoses, neoplasias (tumores) e como cicatrizante. Na categoria mágico-religiosa, é empregada para quebrante em recém-nascido, e como cosmético indicada para limpeza capilar.

A ameixa foi à espécie mais representativa na categoria medicinal, sendo ainda citada para uso veterinário. Suas cascas são indicadas no tratamento de inflamação, gastrite, gripe, dores em geral, problemas no estômago 
e rins, e como cicatrizante. Em relação ao uso veterinário, as cascas são utilizadas no combate a inflamação de bois e vacas.

O mastruz teve seu uso associado exclusivamente à categoria medicinal, onde suas folhas são utilizadas no combate de gripe, dor nos ossos, dor no intestino, dor na coluna, dores em geral, úlcera, gastrite, inflamação, verminoses, neoplasias (tumores) e como cicatrizante.

\section{Transmissão do Conhecimento através das gerações}

Cálculos com o uso do teste de Friedman confirmam a ocorrência de diferença significativa das plantas usadas conforme idade e gênero dos informantes ( $\mathrm{Fr}=5,99$; grau de liberdade $=2$ e $\mathrm{p}<0,05)$. A influência da idade e gênero no conhecimento local vem sendo observado em estudos etnobotânicos realizados com distintos grupos populacionais, tais quais: Phillips e Gentry (1993b); Hanazaki et al. (1996; 2000); Begossi et al. (2002); Pilla et al. (2006) e Silva et al. (2011).

As mulheres apresentaram um conhecimento mais amplo das plantas, corroborado pelo maior número de citações de plantas $(n=638 ; 59,29 \%)$, em relação às citações feitas pelos homens $(n=438 ; 40,71 \%)$. As mulheres dedicadas especialmente aos trabalhos domésticos e aos cuidados com a família mencionam mais as plantas de das categorias mágico-religiosa, ornamental e medicinal. Por outro lado, os homens mostram-se mais familiarizados com plantas da categoria construção, empregadas na fabricação de casas, cercas e cabos de ferramentas agrícolas (Tabela 2). Essas tendências mostraram haver diferença significativa entre os gêneros, dentro de algumas categorias de uso, conforme apontam os cálculos do teste do Qui-quadrado $\left(\square^{2}=40,277\right.$; $\mathrm{p}<0$,0001). Esses dados diferem dos resultados encontrados por Silva et al. (2011), ao avaliar a influência do gênero sobre o conhecimento tradicional em uma comunidade rural na região do semiárido brasileiro.

Tabela 2- Plantas citadas por gênero dos informantes dos núcleos urbanos Juazeiro e Umburana do PA Saco do Juazeiro, São Miguel do Tapuio, Piauí, Brasil

\begin{tabular}{|c|c|c|c|c|}
\hline \multirow{2}{*}{ Categoria de Uso } & \multicolumn{2}{|c|}{ Gênero } & \multirow[b]{2}{*}{ Total $(\%)$} & \multirow{2}{*}{$\mathbf{P}^{a}$} \\
\hline & Feminino $(\%)$ & Masculino (\%) & & \\
\hline Alimentícia & 57,27 & 42,73 & 100 & \multirow{11}{*}{$<0,001$} \\
\hline Artesanal & 50,00 & 50,00 & 100 & \\
\hline Construção & 46,43 & 53,57 & 100 & \\
\hline Cosmético & 40,00 & 60,00 & 100 & \\
\hline Forrageira & 52,17 & 47,83 & 100 & \\
\hline Mágico-religiosa & 100,00 & 0,00 & 100 & \\
\hline Medicinal & 64,26 & 35,74 & 100 & \\
\hline Ornamental & 84,62 & 15,38 & 100 & \\
\hline Produção Energética & 54,17 & 45,83 & 100 & \\
\hline Veterinária & 13,33 & 86,67 & 100 & \\
\hline TOTAL (\%) & 59,29 & 40,71 & 100 & \\
\hline
\end{tabular}

a Teste de Qui-quadrado

Em relação às faixas etárias, observou-se que os adultos, apresentaram maior conhecimento sobre os recursos vegetais do que jovens e idosos (43,12\%, 16,26\% e 40,61\%, respectivamente). Os adultos citaram maior número de plantas para as categorias construção, alimentícia e medicinal, enquanto entre os mais jovens 
destacou-se a medicinal e para os idosos a mágico-religiosa (Tabela 03).

Quando comparados os conhecimentos botânicos de ambos os sexos, relacionando-se com as faixas etárias, obteve-se valor igual a: $\chi^{2}=30,150(\mathrm{p}<0,0036)$, mostrando haver diferença significativa de conhecimento etnobotânico entre todas as faixas etárias estudadas $(\mathrm{p}<0,05)$, sendo que estas diferenças acontecem em determinadas categorias de uso. Diferente do observado por Miranda et al. (2011) em que o uso dos recursos pelos caiçaras em relação a faixa etária se mostraram semelhante, apesar de ser um pouco maior entre os idosos. Segundo os autores, partindo do pressuposto que quanto maior é a idade, maiores são também as chances dos informantes utilizarem as plantas, por terem tido mais tempo de experiência ao longo de suas vidas.

Tabela 3- Plantas citadas por faixa etária dos informantes dos núcleos urbanos Juazeiro me Umburana do PA Saco do Juazeiro, São Miguel do Tapuio, Piauí, Brasil

\begin{tabular}{|c|c|c|c|c|c|}
\hline \multirow{2}{*}{ Categoria de Uso } & \multicolumn{3}{|c|}{ Faixa etária } & \multirow[b]{2}{*}{ Total (\%) } & \multirow{2}{*}{$\mathbf{P a}^{a}$} \\
\hline & Jovem (\%) & Adulto (\%) & Idoso (\%) & & \\
\hline Alimentícia & 15,76 & 47,27 & 36,97 & 100 & \multirow{11}{*}{$<0,036$} \\
\hline Artesanal & 16,67 & 16,67 & 66,67 & 100 & \\
\hline Construção & 14,29 & 49,11 & 36,61 & 100 & \\
\hline Cosmético & 0,00 & 80,00 & 20,00 & 100 & \\
\hline Forrageira & 8,70 & 30,43 & 60,87 & 100 & \\
\hline Mágico-religiosa & 8,33 & 8,33 & 83,33 & 100 & \\
\hline Medicinal & 18,16 & 40,63 & 41,21 & 100 & \\
\hline Ornamental & 15,38 & 38,46 & 46,15 & 100 & \\
\hline Produção Energética & 16,67 & 35,42 & 47,92 & 100 & \\
\hline Veterinária & 0,00 & 66,67 & 33,33 & 100 & \\
\hline TOTAL (\%) & 16,26 & 43,12 & 40,61 & 100 & \\
\hline
\end{tabular}

aTeste de Qui-quadrado

O conhecimento dos recursos vegetais se concentrou entre os adultos, e o desapego entre os jovens, já que as tarefas do campo deixaram de ser obrigação deles, passaram a ter mais acesso aos meios de comunicação, limitando os espaços de construção dos saberes local.

Entre os entrevistados, 100\% afirmaram que os conhecimentos sobre a utilização dos recursos vegetais, especialmente sobre o uso de plantas como remédio, foram transmitidos pelos pais, avós ou familiares. No estudo de Freitas e Fernandes (2006) em uma comunidade rural de Bragança-PA, os conhecimentos sobre o uso de plantas medicinais também foram transmitidos pelos pais. Os investigados também consideraram de grande valor a transmissão do conhecimento botânico para seus sucessores e para a população em geral.

\section{Conclusão}

Os informantes dos núcleos estudados utilizam os recursos obtidos da vegetação nativa para o seu próprio consumo. $\mathrm{O}$ uso das plantas varia conforme a categoria de uso dos recursos, sendo as espécies medicinais e alimentícias as mais utilizadas. Aloe vera se apresentou como a espécie mais versátil, sendo referida para 16 usos.

O uso de recursos naturais é heterogêneo, quando se considera o gênero e faixa etária dos moradores. Homens demonstram conhecer mais espécies da categoria construção, já as mulheres espécies para as categorias 
mágico-religiosa, ornamental e medicinal, provavelmente, pelo tipo de trabalho que cada um desenvolve.

É pertinente destacar que o conhecimento etnobotânico entre os jovens, adultos e idosos entre as categorias de uso são divergentes. Os jovens utilizam mais as plantas medicinais e para produção energética, os adultos as plantas de uso cosmético, veterinário e para construção e os idosos as plantas de uso mágico-religioso, constatando-se que esses informantes utilizam tais plantas devido ao tempo de experimentação no seu dia-a-dia. A utilização e o conhecimento sobre as plantas, em especial, a das utilizadas como medicamentos foi repassada oralmente através dos pais, avós e familiares.

\section{Agradecimentos}

Ao Conselho Nacional de Desenvolvimento Científico e Tecnológico - CNPq, pela concessão da bolsa. A todos os assentados e agregados dos núcleos urbanos Juazeiro e Umburana do PA Saco do Juazeiro, pela prestatividade e disponibilidade em participar neste estudo. À amiga Patrícia Alves pelas prazerosas idas ao campo, a Alexandre Nojoza e Paulo Germano, que me guiaram nas análises estatísticas.

\section{REFERÊNCIAS}

Agra MF, Baracho GS, Nurit K, Basilio IJLD, Coelho, VPM. 2007. Medicinal and poisonous diversity of the flora of "Cariri Paraibano", Brazil. Journal of Ethnopharmacology 111:383-395.

Albuquerque UP, Andrade LHC. 2002a. Conhecimento botânico tradicional e conservação em uma área de caatinga no estado de Pernambuco, Nordeste do Brasil. Acta Botanica Brasilica 16(3): 273 - 285.

Albuquerque UP, Andrade LHC. 2002b. Uso de recursos vegetais na caatinga: o caso do agreste do estado de Pernambuco (Nordeste do Brasil). Interciencia 27(7): 336-346.

Albuquerque UP, Andrade L.H.C, Silva A.C.O. 2005. Use of plant resources in a seasonal dry forest (Northeastern Brazil). Acta Botanica Brasilica 19(1): 27-38.

Alves RNA, Alan-Angeles GS, Wedson MSS, Raynner-Rilke DB. 2007. Utilização e comércio de plantas medicinais em

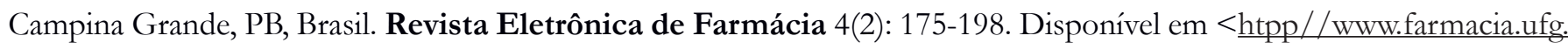
br/revista/vol4 2/capa.ht> (acesso em 15 /07/2011).

Amaral CN, Guarim Neto G. 2008. Os quintais como espaços de conservação e cultivo de alimentos: um estudo na cidade de Rosário Oeste (Mato Grosso, Brasil). Boletim do Museu Paraense Emílio Goeldi. Ciências Humanas 3(3): 329-341.

Amorozo MCM, 1996. A abordagem etnobotânica na pesquisa de plantas medicinais, in: STASI, Cláudio, L. (Ed.), Plantas medicinais: Arte e ciências. Universidade Estadual Paulista, São Paulo, pp. 47-67.

Amorozo MCM. 2002. Uso e diversidade de plantas medicinais em Santo Antonio do Leverger, MT, Brasil. Acta Botanica Brasilica 16(2): 189-203. 
Byng JM et al.2016. An update of the Angiosperm Phylogeny Group classification for the orders and families of flowering plants: APG IV. Botanical Journal of the Linnean Society. 181 (1): 1-20.

Appolinário F. 2006. As etapas do trabalho científico. pp. 73-83. In: Metodologia da ciência: filosofia e prática da pesquisa. São Paulo: Thomson Learning.

Azevedo SKS, Silva IM. 2006. Plantas medicinais e de uso religioso comercializadas em mercados e feiras livres no Rio de Janeiro, RJ, Brasil. Acta Botanica Brasilica 1(20): 185-194

Ayres M, Ayres Jr M, Ayres DL, Santos AS. 2007. BioEstast. Versão 5.0. Sociedade Civil de Marmirauá, MCTCNPq, Belém.

Begossi A, Leitão Filho HF, Richerson PJ. 1993. Plant uses in a brazilian coastal fishing community (Buzios Island). Journal of Ethnobiology 13(2): 233-256

Begossi A. 2001. Resiliência e populações neotradicionais: as caiçaras (Mata Atlântica) e os caboclos (Amazônia, Brasil). In: Diegues, A.C, Moreira, A.C.C (Orgs.). Espaços e recursos naturais de uso comum. São Paulo: NUPAUB, pp.205-236.

Begossi A, Hanazaki N, Tamashiro JY. 2002. Medicinal plants in the atlantic forest (Brazil): knowledge, use and conservation. Human Ecology 30: 281-299.

Bernard HR. Research methods in cultural Anthropology. 1988. Sage. Newbury Park, CA, EEUU.

Boscolo OH, Valle LSV. 2008. Plantas de uso medicinal em Quissamã, Rio de Janeiro, Brasil. Iheringia, Série Botânica 63(2): 263-277.

Botrel RT, Rodrigues LA, Gomes LJ, Carvalho DA, Fontes MAL, 2006. Uso da vegetação nativa pela população local no município de Ingaí, MG, Brasil. Acta Botanica Brasilica 20(1): 143-156

Camou-Guerrero A, Reyes-Garcia V, Martínez-Ramos M, Casas A. 2008. Knowledge and use value of plant species in a Rarámuri community: a gender perspective for conservation. Human Ecology 36: 259-272.

Carniello MA, Silva RS, Cruz MAB, Guarim Neto G. 2010. Quintais urbanos de Mirassol D’Oeste-MT, Brasil: uma abordagem etnobotânica. Acta Amazonica 40 (3): 451-470.

Cepro - Fundação Centro de Pesquisa Econômicas e Sociais. 2007. Perfil dos municípios. Teresina: Fundação CEPRO.

Chaves EMF, Barros RFM. 2008. Resource use of the flora ef the Brushwood Vegetation in Cocal County, Piauí, Brasil. Functional Ecosystems and Comunities 2: 21-31.

Choudhary K, Singh M, Pillai U. 2008. Ethnobotanical survey of Rajasthan - an update. Journal of Botany $1(2): 38-45$.

Coutinho DF. 2002 Estudo etnobotânico de plantas medicinais utilizadas em comunidades indígenas no estado do Maranhão-Brasil. Visão Acadêmica 3:7-12. 
Coimbra TJ, Araújo JLL, Diodato MA. 2008. Turismo no semiárido - possibilidade de inclusão social e redução da pobreza em assentamento rural. Revista Ciência Administração 14(2): 279-290.

David M, Pasa MC. 2016. Ribeirinhos e recursos vegetais: a Etnobotânica em Bonsucesso, Várzea Grande, Mato Grosso. Boletim do Grupo de Pesquisa da Flora, Vegetação e Etnobotânica 1 (8) : 1-15.

De-la-Cruz H, Vilcapoma G, Zevallos PA.2007. Ethnobotanical study of medicinal plants used by the andean people of Canta, Lima, Peru. Journal of Ethnopharmacology 111: 284-294

Diegues AC. 2002. O mito moderno da natureza intocada.4 ed. São Paulo.

Di Stasi LC, Oliveira GP, Carvalhaes MA, Queiroz-Junior M, Tien OS, Hakinami SH, Reis MS.2002. Medicinal plants popularly used in the Brazilian Tropical Atlantic Forest. Fitoterapia 73: 69-91.

Duarte GSD, Pasa MC. 2015. Agrobiodiversidade e a etnobotânica na comunidade São Benedito, Poconé, Mato Grosso, Brasil. Interações 17 (2): 247-256.

Ferraz JSF, Albuquerque UP, Meunier IMJ. 2006. Valor de uso e estrutura de vegetação lenhosa às margens do riacho do Navio, Floresta, PE, Brasil. Acta Botanica Brasilica 20(1): 125-134.

Fonseca-Kruel VS, Peixoto AL. 2004. Etnobotânica na reserva extrativista marinha de Arraial do Cabo, RJ, Brasil. Acta Botanica Brasilica 18(1): 177-190.

Freitas, JC, Fernandes, MEB. 2006. Uso de plantas medicinais pela comunidade de Enfarrusca, Bragança, Pará. Ciências Naturais 1(3): 11-26.

Franco EAPA, Barros RFM. 2006. Uso e diversidade de plantas medicinais no Quilombo Olho D'água dos Pires, Esperantina, Piauí. Revista Brasileira de Plantas Medicinais 8(3): 78-88.

Gavin MC, Anderson GJ. 2007. Socieconomic predictors of forest use values in the Peruvian Amazon: a potential tool for biodiversity conservation. Ecological Economics 60: 752-762.

Hanazaki N, Leitão-Filho HF, Begossi A. 1996. Uso de recursos na Mata Atlântica: o caso da Ponta do Almada (Ubatuba, Brasil). Interciência 21: 268-276.

Hanazaki N, Tamashiro JY, Leitão-Filho HF, Begossi A. 2000. Diversity of plants uses in two caiçara communities from the atlantic forest coast, Brazil. Biodiversity and Conservation 9: 597-615.

Hanazaki N, Souza VC, Rodrigues RR. 2006. Ethnobotany of rural people from the boundaries of Carlos Botelho state park, São Paulo state, Brasil. Acta Botanica Brasilica 20(4): 887-898.

Lemos JR. 2001. Plantas da caatinga com potencial forrageiro, Parque Nacional Serra da Capivara, estado do Piauí. Revista Pesquisa em Foco 9(14): 91-100.

Lista de espécies da flora do Brasil 2016. < http://floradobrasil.jbrj.gov.br/2012> (acesso 04/01/2016).

Lopes LCM, Lobão AQ. 2013. Etnobotânica em uma comunidade de pescadores artesanais no litoral norte do 


\section{Espírito Santo, Brasil. Boletim do Museu de Biologia Mello Leitao 32:29-52.}

Marinho ML, Alves MS, Rodrigues MLC, Rotondano, TEF, Vidal, IF, Silva, WW, Athayde, ACR. 2007. A utilização de plantas medicinais em medicina veterinária: um resgate do saber popular. Revista Brasileira de Plantas Medicinais 9(3):64-69.

Miranda, TM, Hanazaki N, Govone JS, Alves DMM. 2011. Existe utilização efetiva dos recursos vegetais conhecidos em comunidades caiçaras da Ilha do Cardoso, estado de São Paulo, Brasil? Rodriguésia 62(1): 153169.

Mobot. Missouri Botanical Garden. W3 tropicos. <http://mobot.mobot.org/W3T/Search/vast.html $>$ (acesso em 15/01/2016).

Montelles R, Pinheiro CU. 2007. Plantas medicinais em um quilombo maranhense: uma perspectiva etnobotânica. Revista de Biologia e Ciências da Terra 7(2): 38-48.

Mori SA, Silva LAM, Lisboa G, Coradin L. 1989. Manual de manejo do herbário fanerogâmico. 2. ed. CEPLAC: Ilhéus, 104p.

Nair PKP. 2004. The enigma of tropical homengardens. Agroflorestry Systems 61: 135-152.

Nesheim I, Dhillion SS, Stolen KA. 2006. What happens to traditional knowledge and use of natural resources when people migrate? Human Ecology 34: 99-131.

Oliveira FCS, Barros RFM, Moita-Neto JM. 2010. Plantas medicinais utilizadas em comunidades rurais de Oeiras, semiárido piauiense. Revista Brasileira de Plantas Medicinais 12 (3) 81-301.

Pasa, MC. 2011. Saber local e medicina popular: a etnobotânica em Cuiabá, Mato Grosso, Brasil. Ciência Humana 6(1): 179-196.

Pilla MAC, Amorozo MCM, Furlan A. 2006. Obtenção e uso das plantas medicinais no distrito de Martins Francisco, Município de Mogi-Mirim, SP, Brasil. Acta Botanica Brasilica 20(4): 789-802.

Pinheiro CUB, Santos VM, Ferreira FRR. 2005. Usos de subsistência de espécies vegetais na Região da Baixada Maranhense. Amazônia: Ciência \& Desenvolvimento 1(1): 235-250.

Pinto EPP, Amorozo MCM, Furlan A. 2006. Conhecimento popular sobre plantas medicinais em comunidades rurais de mata atlântica - Itacaré, BA. Acta Botanica Brasilica, 20(4): 751-762.

Phillips O, Gentry AH. 1993a. The useful plants of Tambopata, Peru: I. Statistical hypoteses tests with a new quantitative technique. Economic Botany 47(1): 15-32.

1993b. The useful plants of Tambopata, Peru: II. Additional, hypothesis testing in quantitative ethnobotany.

Economic Botany 47(1): 33-43.

Phillips O, Gentry AH, Reynel C, Wilkin P, Gálvez-Durand C. 1994. Quantitative ethnobotany and amazonian conservation. Conservation Biology 8(1): 225-248. 
Reyes-Garcia V, Valdez V, Huanca T, Leonard WR, Wilkie D. 2005. Knowledge and consumption of wild plants: a comparative study in two Tsimane' villages in the Bolivian Amazon. Ethnobotany Research \& Applications 3:201-207.

Reyes- Garcia V, Valdez V, Huanca T, Leonard WR, Mcdade T. 2007. Economic development and local ecological knowledge: a deadlock? Quantitative Research from a native Amazonian society. Human Ecology 35:371-377.

Rico-Gray V, Garcia-Franco JG, Chemas A, Puch A, Sima P. 1990. Species composition, similarity, and structure of Mayan Homegardens in Tixpeual and Tixcacaltuyub, Yucatan, Mexico. Economic Botany 44: 470-487.

Rocha EA, Moreira RCT, Costa LCB, Costa RCS. 2002. Abordagem Etnobotânica acerca do uso de plantas medicinais na Vila Cachoeira, Ilhéus, Bahia, Brasil. Acta Farmacéutica Bonaerense 21(3): 205-11.

Rodrigues LA, Carvalho DA, Gomes LJ, Botrel RT. 2002. Espécies vegetais nativas usadas pela população local em Luminárias-MG. Boletim Agropecuário 52: 1-34.

Rossato SC. 1996. Uso de plantas do litoral norte do estado de São Paulo. Dissertação (Mestrado em Ciências Biológicas - Botânica). Departamento de Ecologia, IB/Universidade de São Paulo, São Paulo.

Rossato SC, Leitão Filho HF, Begossi A. 1999. Ethnobotany of caiçaras of the Atlantic Forest Coast (Brazil). Economic Botany 53(4): 387-395.

Silva ACO, Albuquerque UP. 2005. Woody medicinal plants of the caatinga in the state of Pernambuco (Northeast Brazil). Acta Botanica Brasilica 19(1) 17-26.

Silva AJR, Andrade LHC. 2005. Etnobotânica nordestina: estudo comparativo da relação entre comunidades e vegetação na Zona do Litoral - Mata do Estado de Pernambuco, Brasil. Acta Botanica Brasilica 19(1): 45-60.

Silva MP. 2010. Etnobotânica de comunidades rurais da Serra de Campo Maior - Piauí, Brasil. 2010.173f. Dissertação (Mestrado em Desenvolvimento e Meio Ambiente) - Programa de Pós-Graduação em Desenvolvimento e Meio Ambiente. Universidade Federal do Piauí, Teresina.

Silva FS, Ramos MA, Hanazaki N, Albuquerque UP. 2011. Dynamics of traditional knowledge of medicinal plants in a rural community in the Brazilian semi-arid region. Revista Brasileira de Farmacognosia 21(3) :382-391.

Souza CD, Felfili JM. 2006. Uso de plantas medicinais na região de Alto Paraíso de Goiás, GO, Brasil. Acta Botanica Brasilica 20(1): 135-142

Stagegaard J, Sorensen M, Kvist LP. 2002. Estimations of the importance of plant resource extracted by inhabitants of the Peruvian Amazon flood plains. Urban \& Fischen Verlag 5(2): 103-122.

Torres DF, Oliveira ES, Alves RRN, Vasconcelos A. 2009. Etnobotânica e Etnozoologia em unidades de conservação: uso da biodiversidade na Apa de Genipabu, Rio Grande do Norte, Brasil. Interciência 34(9): 623-629.

Valadão LM, Amorozo MCM, Motta DG .2006. Produção de alimentos na unidade domiciliar, dieta e estado 
nutricional: a contribuição dos quintais em um assentamento rural no estado de São Paulo. p. 93-118. In: Albuquerque,U.P.; Almeida, C.F.C.B.R.A. (Org.). Tópicos em conservação e etnobotânica de plantas alimentícias. Recife: NUPEEA.

Vendruscolo GSE, Mentz LU. 2006. Estudo da concordância das citações de uso e importância das espécies e famílias utilizadas como medicinais pela comunidade do bairro Ponta Grossa, Porto Alegre, RS, Brasil. Acta Botanica Brasilica 20(2): 367-382.

Vieira S. 2003. Bioestatística: tópicos avançados. Campus, Rio de Janeiro. 212p.

Vieira FJ, Santos LGP, Barros RFM, Araújo JLL. 2008. Quilombola of Macacos Community, São Miguel do Tapuio City, Piauí State: History, Use and Conservation of Plant Resources. Functional Ecossystems and Comunities 2: 81-87.

Voeks RA. 2007. Are women reservoirs of traditional plant knowlegde? Gender, etnobotany and globalization in northeast Brazil. Singapore Journal os Tropical Geography 28: 7-20.

Ubom RM. 2010. Ethnobotany and biodiversidy conservation in the Niger Delta, Nigeria. International Journal of Botany 6(3): 310-322. 